Supporting information:

\title{
Thyroid Receptor Ligands. 6. A High Affinity "Direct Antagonist" Selective for the Thyroid Hormone Receptor
}

Experimental procedures and analytical data

Konrad Koehler, ${ }^{\dagger}$ Sandra Gordon, ${ }^{\dagger}$ Peter Brandt, ${ }^{\dagger}$ Bo Carlsson,,${ }^{\dagger}$ Anna Bäcksbro-Saeidi, ${ }^{\dagger}$ Theresa Apelqvist, ${ }^{\dagger}$ Peter Agback, ${ }^{\dagger}$ Gary J. Grover, ${ }^{\dagger}$ William Nelson, ${ }^{\dagger}$ Marlena Grynfarb,${ }^{\dagger}$ Mathias Färnegårdh, ${ }^{\dagger}$ Stefan Rehnmark, ${ }^{\dagger}$ and Johan Malm ${ }^{\dagger} *$

${ }^{\dagger}$ Karo Bio AB, Novum, Huddinge SE-141 57, Sweden.

${ }^{\ddagger}$ Product Safety Laboratories, Eurofins Scientific, Dayton, NJ, USA

* Corresponding author: Johan Malm,

Karo Bio AB, Novum, S-141 57, Sweden.

Tel: +46-8-608 6046

Fax: +46-8-774 8261

E-mail:johan.malm@karobio.se 


\section{Experimental Procedures}

Docking of 6 into the thyroid hormone receptor beta. A partial homology model of TR $\beta$ in the antagonist conformation was constructed using the crystallographic structure of $h \mathrm{TR} \beta / 3-[3,5-$ dibromo-4-(3-isopropyl-4-hydroxyphenoxy)phenyl]propionate (7) (in which $\mathrm{H} 12$ is in the canonical agonist conformation; PDB accession code 2J4A) and hRAR-alpha/BMS-614 (H12 is in the canonical antagonist conformation; PDB accession code 1DKF). The coordinates from residues 147 to 395 (includes helices 1-11) and 7 were taken from the TR $\beta$ structure and coordinates from residues 407 to 417 (includes helix 12) were extracted RAR $\alpha$ structure. The residues extracted from the RAR structure were mutated and renumbered to the corresponding residues in the TR-beta protein using the alignment (Clustal W version 1.82) below:

hRAR-alpha 379

901234567890123456789012345678901234567890

hTR-beta 369

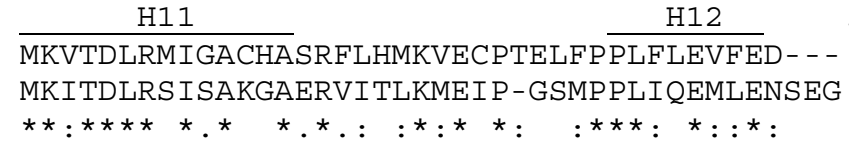

Since there is one deletion in RAR $\alpha$ sequence relative to TR $\beta$ in the loop between H11 and H12, the conformation of part of this loop (residues 392 to 396) was modeled using the RAPPER server $^{1,2}$ with the "searchPBD for compatible fragments", "use contact filter", and "compute molecular mechanics potential energy" options all turned on. The hybrid structure was then imported into Maestro version 7.5 (Schrödinger, LLC, New York, New York, 10036), 7 was mutated into 6 using the build option of Maestro, and hydrogens were added to all atoms. The structure was then partially optimized by freezing all non-hydrogen atoms except those in the ligand, residues 392 to 392, and protein side-chains within $7.0 \AA$ of the ligand with the OPLS_2005 force field and default settings in MacroModel BatchMIn version 9.1 (Schrödinger, LLC).

Chemistry. General Methods. Mikrokemi, Uppsala, Sweden, carried out the elemental analysis. Flash chromatography was performed on silica gel 60 (230-400 mesh) from Sigma Aldrich. Analytical TLC was carried out on silica gel $60 \mathrm{~F}_{254}$ from Sigma Aldrich. ${ }^{1} \mathrm{H}$ NMR spectra were detected on a Varian or Bruker spectrometer at 200,300 or $500 \mathrm{MHz} .{ }^{13} \mathrm{C}$ NMR spectra were recorded on a Bruker Avance spectrometer measured at $125.76 \mathrm{MHz}$. Chemical shifts $(\delta)$ are expressed in ppm. Mass spectra were recorded on a Perkin-Elmer, API 150Ex spectrometer, with turbo "ion spray" in negative ion mode (ES-1), using a Zorbax SB-C8 column (LC-MS). All solvents and reagents were purchased from commercial sources as analytical grade and used without further purification.

3-\{3,5-Dibromo-4-[4-hydroxy-3-isopropyl-5-((E)-2-pyridin-4-yl-vinyl)phenoxy]phenyl\}propionic acid (6). To a stirred solution of methyl 3-[3,5-dibromo-4-(3-isopropyl-4methoxyphenoxy)phenyl]propionate ${ }^{3}(8.86 \mathrm{~g}, 18.2 \mathrm{mmol})$ in benzene $(250 \mathrm{ml})$ at room temperature, nitric acid $(10.5 \mathrm{ml}, 65 \%)$ was added drop-wise. After stirring overnight the $\mathrm{pH}$ of the reaction mixture was adjusted to $\mathrm{pH} 7$ with saturated sodium bicarbonate. The organic phase was separated and the aqueous phase extracted with dichloromethane $(2 \times 50 \mathrm{ml})$. The combined organic extracts were concentrated and the residue purified by flash chromatography (n-hexane/ethyl acetate 4:1) affording $9.50 \mathrm{~g}$ (98\%) of methyl 3-[3,5-dibromo-4-(3-isopropyl-4-methoxy-5-nitrophenoxy)phenyl]propionate as a yellow solid. ${ }^{1} \mathrm{H}$ NMR $\left(200 \mathrm{MHz}, \mathrm{CDCl}_{3}\right) \delta 1.25(\mathrm{~d}, 6 \mathrm{H}), 2.65(\mathrm{~m}, 2 \mathrm{H}), 2.98$ $(\mathrm{m}, 2 \mathrm{H}), 3.40(\mathrm{~m}, 1 \mathrm{H}), 3.79(\mathrm{~s}, 3 \mathrm{H}), 3.85(\mathrm{~s}, 3 \mathrm{H}), 6.95(\mathrm{~s}, 1 \mathrm{H}), 7.05(\mathrm{~s}, 1 \mathrm{H}), 7.50(\mathrm{~s}, 2 \mathrm{H})$.

To a solution of methyl 3-[3,5-dibromo-4-(3-isopropyl-4-methoxy-5-nitrophenoxy)phenyl]propionate $(9.50 \mathrm{~g}, 17.9 \mathrm{mmol})$ in ethanol $(650 \mathrm{ml})$ was added sodium dithionite $(16.0 \mathrm{~g}, 91.9$ mmol). The reaction mixture was stirred at $70^{\circ} \mathrm{C}$ overnight. The reaction mixture was concentrated and a saturated aqueous solution of sodium bicarbonate $(250 \mathrm{ml})$ was added to the residue. 
Extraction with ethyl acetate $(2 \times 150 \mathrm{ml})$, washing of the organic extracts with brine $(250 \mathrm{ml})$, drying $\left(\mathrm{MgSO}_{4}\right)$, filtering and concentration gave a residue which was purified by flash chromatography (n-hexane/ethyl acetate 3:2). The thus obtained product was converted to its hydrochloride salt by treatment with $\mathrm{HCl}$ in methanol $(1.25 \mathrm{~N})$. The salt was recrystallized from methanol/diethyl ether affording $6.00 \mathrm{~g}$ (57\%) of pure methyl 3-[3,5-dibromo-4-(3-amino-5isopropyl-4-methoxyphenoxy)phenyl] propionate hydrochloride as a white solid. ${ }^{1} \mathrm{H}$ NMR (200 MHz, DMSO-d $\left.\mathrm{d}_{6}\right) \delta 1.25(\mathrm{~d}, 6 \mathrm{H}), 2.79(\mathrm{~m}, 2 \mathrm{H}), 2.98(\mathrm{~m}, 2 \mathrm{H}), 3.25(\mathrm{~m}, 1 \mathrm{H}), 3.65(\mathrm{~s}, 3 \mathrm{H}), 3.85(\mathrm{~s}$, $3 \mathrm{H}), 6.55(\mathrm{~s}, 1 \mathrm{H}), 6.64(\mathrm{~s}, 1 \mathrm{H}), 7.80(\mathrm{~s}, 2 \mathrm{H})$.

To a vigorously stirred mixture of methyl 3-[3,5-dibromo-4-(3-amino-5-isopropyl-4-methoxyphenoxy)phenyl]propionate hydrochloride $(5.22 \mathrm{~g}, 9.70 \mathrm{mmol})$, methanol $(300 \mathrm{ml})$ and an aqueous solution of hydrochloric acid $(100 \mathrm{ml}, 37 \%)$, sodium nitrite $(1.11 \mathrm{~g}, 16.0 \mathrm{mmol})$ in water $(40 \mathrm{ml})$ was added dropwise for 20 min. while keeping the temperature in the reaction flask between -15 and $-20{ }^{\circ} \mathrm{C}$. After $40 \mathrm{~min}$, a solution of potassium iodide $(9.92 \mathrm{~g}, 59.8 \mathrm{mmol})$ in water $(40 \mathrm{ml})$ was added slowly at $-15{ }^{0} \mathrm{C}$. The reaction mixture was kept for $60 \mathrm{~min}$. at -15 to $0{ }^{\circ} \mathrm{C}$, and at 0 to $5{ }^{0} \mathrm{C}$ for an additional hour. The reaction mixture was extracted with dichloromethane $(3 \mathrm{x} 150 \mathrm{ml})$, the combined organic extracts washed with saturated sodium bicarbonate $(250 \mathrm{ml})$, saturated sodium thiosulphate $(2 \mathrm{x} 150 \mathrm{ml})$ and with brine $(250 \mathrm{ml})$. After drying $\left(\mathrm{MgSO}_{4}\right)$, filtration and concentration the crude product was subjected to flash chromatography (n-hexane/ethyl acetate 9:1) to give $3.30 \mathrm{~g}(55 \%)$ of methyl 3-[3,5-dibromo-4-(3-iodo-5-isopropyl-4-methoxyphenoxy)phenyl] propionate as a light yellow solid. ${ }^{1} \mathrm{H}$ NMR $\left(200 \mathrm{MHz}, \mathrm{CDCl}_{3}\right) \delta 1.25(\mathrm{~d}, 6 \mathrm{H}), 2.65(\mathrm{~m}, 2 \mathrm{H}), 2.98$ (m, 2H), $3.25(\mathrm{~m}, 1 \mathrm{H}), 3.78(\mathrm{~s}, 3 \mathrm{H}), 3.82(\mathrm{~s}, 3 \mathrm{H}), 6.80(\mathrm{~s}, 1 \mathrm{H}), 6.85(\mathrm{~s}, 1 \mathrm{H}), 7.50(\mathrm{~s}, 2 \mathrm{H})$.

To a stirred solution of methyl-3-[3,5-dibromo-4-(3-iodo-5-isopropyl-4-methoxy-phenoxy)phenyl] propionate $(3.30 \mathrm{~g}, 5.39 \mathrm{mmol})$ in dichloromethane $(180 \mathrm{ml})$ was added boron trifluoride dimethyl sulfide $(13.5 \mathrm{ml}, 128.6 \mathrm{mmol})$ slowly at room temperature. The reaction mixture was left stirring overnight in the dark and then carefully poured over ice-water, the organic layer separated and the water layer extracted with dichloromethane. The combined organic phases were dried over $\mathrm{MgSO}_{4}$, filtered and concentrated. Flash chromatography (n-hexane/ethyl acetate 9:1) gave $2.67 \mathrm{~g}$ (83\%) of methyl 3-[3,5-dibromo-4-(3-iodo-5-isopropyl-4-hydroxyphenoxy)phenyl] propionate as a light yellow solid. ${ }^{1} \mathrm{H}$ NMR $\left(300 \mathrm{MHz}, \mathrm{CDCl}_{3}\right) \delta 1.00(\mathrm{~d}, 6 \mathrm{H}), 2.46(\mathrm{~m}, 2 \mathrm{H}), 2.73(\mathrm{~m}, 2 \mathrm{H}), 3.06(\mathrm{~m}$, $1 \mathrm{H}), 3.49$ (s, 3H), 4.91 (s, 1H), 6.57 (m, 2H), 7.24 (s, 2H).

A solution of methyl 3-[3,5-dibromo-4-(3-iodo-5-isopropyl-4-hydroxyphenoxy)phenyl]propionate $(2.11 \mathrm{~g}, 3.52 \mathrm{mmol})$, diisopropylethyl amine $(1.36 \mathrm{~g}, 10.5 \mathrm{mmol})$ and lithium chloride $(0.17 \mathrm{~g}, 4 \mathrm{mmol})$ in dry DMF $(60 \mathrm{ml})$ was degassed with nitrogen for 5 minutes, followed by the addition of palladium(II)acetate $(80 \mathrm{mg}, 0.36 \mathrm{mmol})$. After stirring for 5 minutes at room temperature, 4-vinylpyridine $(1.12 \mathrm{~g}, 10.7 \mathrm{mmol})$ was added by syringe and the reaction mixture heated at $75{ }^{\circ} \mathrm{C}$ overnight. The reaction mixture was evaporated to dryness and purified by flash chromatography (as a gradient from n-hexane/ethyl acetat $4: 1$ to $100 \%$ ethyl acetate) to give $1.26 \mathrm{~g}$ (62\%) of methyl 3-\{3,5-dibromo-4-[4-hydroxy-3-isopropyl-5((E)-2-pyridin-4-yl-vinyl)phenoxy]phenyl $\}$ propionate as a yellow solid. ${ }^{1} \mathrm{H}$ NMR $\left(300 \mathrm{MHz}, \mathrm{CDCl}_{3}\right) \delta 1.02(\mathrm{~d}, 6 \mathrm{H}), 2.45(\mathrm{~m}, 2 \mathrm{H})$, $2.73(\mathrm{~m}, 2 \mathrm{H}), 3.02(\mathrm{~m}, 1 \mathrm{H}), 3.48(\mathrm{~s}, 3 \mathrm{H}), 6.53(\mathrm{~d}, 1 \mathrm{H}), 6.58(\mathrm{~d}, 1 \mathrm{H}), 6.80(\mathrm{~d}, 1 \mathrm{H}), 7.01(\mathrm{~m}, 2 \mathrm{H})$, 7.25 (s, 2H), 7.56 (d, 1H), $8.22(\mathrm{~m}, 2 \mathrm{H})$; MS (ES) m/z 576.4 (M-1).

To a stirred solution of methyl 3-\{3,5-dibromo-4-[4-hydroxy-3-isopropyl-5-(2-pyridin-4-ylvinyl)phenoxy]phenyl $\}$ propionate $(0.88 \mathrm{~g}, 1.53 \mathrm{mmol})$ in tetrahydrofuran $(36 \mathrm{ml})$, lithium hydroxide $(8 \mathrm{ml}, 1 \mathrm{~N}, 8 \mathrm{mmol})$ was added drop-wise. The reaction was stirred at room temperature overnight. After concentration water $(5 \mathrm{ml})$ was added and the $\mathrm{pH}$ adjusted to 7 with aqueous hydrochloric acid $(1 \mathrm{~N})$; the thus precipitated solid was filtered, washed with cold water and dried to give $0.80 \mathrm{~g}$ (94\%) of 3-\{3,5-dibromo-4-[4-hydroxy-3-isopropyl-5-(2-pyridin-4-yl-vinyl)phenoxy]phenyl \}propionic acid as a light yellow solid. ${ }^{1} \mathrm{H}$ NMR (MeOD-d3) $\delta 1.18(\mathrm{~d}, 6 \mathrm{H}, \mathrm{J}=6.6, \mathrm{H} 17$ ), 
$2.52(\mathrm{t}, 2 \mathrm{H}, \mathrm{J}=7.6, \mathrm{H} 2), 2.93(\mathrm{t}, 2 \mathrm{H}, \mathrm{J}=7.6, \mathrm{H} 3), 3.31(\mathrm{~m}, 1 \mathrm{H}, \mathrm{H} 16), 6.65$ (br d, 1H, J= 2.8, H11), 6.79 (br d, 1H, J= 2.8, H15), 6.93 (d, 1H, J= 16.1, H19), 7.55 (m, 2H, H21, H24), 7.60 (s, 2H, H5, H9), 7.80 (d, 1H, J= 16.1 Hz, H18), 8.44 (m, 2H, H22, H23); ${ }^{13} \mathrm{C}$ NMR (DMSO-d6) $\delta: 22.8$ (2C, C17), 28.4 (1C, C16), 32.0 (1C, C3), 39.5 (1C, C2), 110.1 (1C, C15), 114.8 (1C, C11), 119.3 (2C, C6, C8), 122.4 (2C, C21, C24), 126.5 (1C, C19), 126.7 (1C, C14), 130.4 (1C, C18), 134.0 (2C, C5, C9), 139.7 (1C, C12), 143.5 (1C, C4), 147.4 (1C, C20), 148.0 (1C, C7), 148.2 (1C, C13), 150.1 (2C, C22, C23), 151.9 (1C, C10), and 179.7 (1C, C1). LC-MS (ES) m/z 559.9 (M-1).

\section{Ring numbering:}

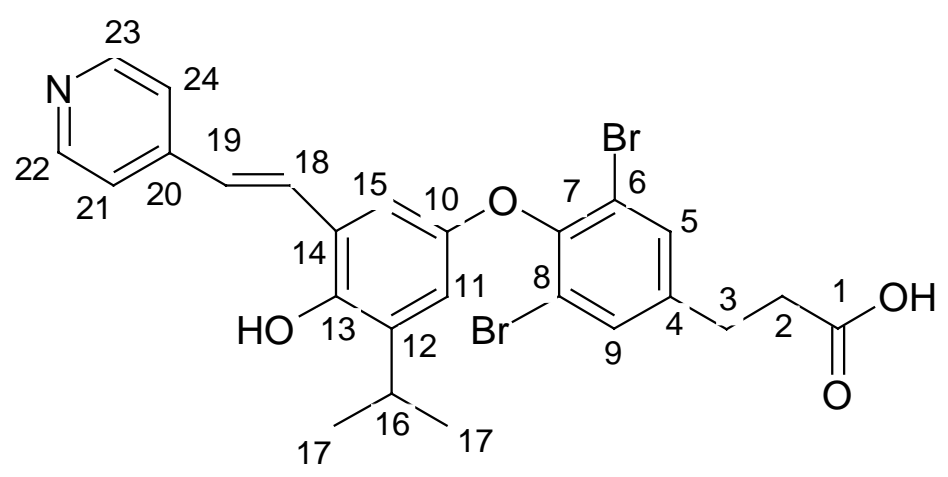

\section{Combustion analyses for $6\left(\mathrm{C}_{14} \mathrm{H}_{18} \mathrm{Br}_{2} \mathrm{O}_{3}\right)$ :}

\begin{tabular}{|c|c|c|c|c|c|}
\hline \multicolumn{3}{|c|}{ Found (\%) } & \multicolumn{3}{c|}{ Calculated ((\%) } \\
\hline $\mathrm{C}$ & $\mathrm{H}$ & $\mathrm{N}$ & $\mathrm{C}$ & $\mathrm{H}$ & $\mathrm{N}$ \\
\hline 53.7 & 4.2 & 2.7 & 53.5 & 4.1 & 2.5 \\
\hline
\end{tabular}

TR-binding assay, vector constructs, generation of reporter cell lines (TRAF) and assay procedure. These assays and procedures have been described in detail previously in reference ${ }^{4}$, including cited references therein.

In vivo experiment. 4 Week old male Sprague Dawley rats were placed on special cholesterol diet (Paigan diet D12336 from Research Diets, USA) for 2 weeks at Taconics in Denmark, then shipped to KaroBio AB (CRC, Clinical Research Centre (KFC)), CRC animal facility. The animals were placed in rat cages, 3 animals/cage (Number of animals per treatment group was 6) except for the reference compound group (4 rats/cage), with free access to food (D12336) and water (tap water), 12:12 light dark cycle (light 06:00 - 18:00), $20 \mathrm{C}$ room temp, 40\% humidity. The animals were acclimated to the new conditions for 6 days before starting the treatment. One day before start of treatment body weight was taken, and the animals marked on the tail (fine surgical marker pen) for individual tracking. The animals were dosed p.o. (between 12:00 - 15:00) by oral gavage, once daily, with compounds dissolved in vehicle (PEG-400 in water 54\%, 10\% DMSO) for 7 days. At the end of the study all animals were fasted over night, at least $12 \mathrm{~h}$ fasting, before termination of the study. Termination of the study, the animals, one at a time, were anesthetized by isoflurane inhalation and kept under anesthesia for monitoring of the heart rate by 3 lead ECG (ADinstrument). ECG was monitored for 2-3 minutes, and immediately after that the animals were 
placed in a container with constant flow of $\mathrm{CO} 2$ gas for 2 minute until they were dead. Bodyweight was measured followed by rapid opening of thorax and collection of blood through open heart puncture (right ventricle) by $18 \mathrm{G}$ needle connected to 5 or $10 \mathrm{ml}$ syringe. The blood was immediately transferred to VenoSafe $(3.5 \mathrm{ml})$ GEL+Clot Act Vacutainer tubes kept at room temperature. Serum was separated by centrifugation at $2500 \mathrm{rpm}$ (Sorvall RT6000B), 4C, for 15 minutes, and transferred to eppendorf tubes. LDL cholesterol was determined using Cypress Diagnostics \# HB028.

\section{References}

1. de Bakker, P. I.; DePristo, M.; et al. (2005). RAPPER server.

2. DePristo, M. A.; de Bakker, P. I.; et al. Ab initio construction of polypeptide fragments: efficient generation of accurate, representative ensembles. Proteins, 2003, 51, 41-55.

3. Yokoyama, N.; Walker, G. N.; Main, A. J.; Stanton, J. L.; Morrissey, M. M.; Boehm, C.; Engle, A.; Neubert, A. D.; Wasvary, J. M.; Stephan, Z. F.; Steele, R. E. Synthesis and structure-activity relationships of oxamic acid and acetic acid derivatives related to L-thyronine. J. Med. Chem., 1995, 38, 695-707.

4. Ye, L.; Li, Y. L.; Mellström, K.; Mellin, C.; Bladh, L. G.; Koehler, K. F.; Garg, N.; Garcia Collazo, A. M.; Litten, C.; Husman, B.; Persson, K.; Ljunggren, J.; Grover, G.; Sleph, P. G.; George, R.; Malm, J. Thyroid receptor ligands. 1. Agonist ligands selective for the thyroid receptor beta1. J. Med. Chem., 2003, 46, 1580-1588. 